\title{
Effects of myrrh on intra-oral mucosal wounds compared with tetracycline- and chlorhexidine- based mouthwashes
}

This article was published in the following Dove Press journal:

Clinical, Cosmetic and Investigational Dentistry

29 August 201I

Number of times this article has been viewed

\author{
Azizah Al-Mobeeriek \\ Department of Oral Medicine and \\ Diagnostic Sciences, College of \\ Dentistry, King Saud University, \\ Riyadh, Saudi Arabia
}

Aim: To evaluate the effect of myrrh compared with chlorhexidine gluconate- and tetracyclinecontaining mouthwashes on wound healing over time in an animal model.

Methods: A unilateral incision on the right buccal mucosa was made, and the wound was irrigated with myrrh-, chlorhexidine gluconate-, or tetracycline-based mouthwashes at various time intervals. Clinical and histological examination was performed for all the groups.

Results: It was found that the myrrh suspension promotes healing and repair of damaged tissue when used over a short period of time (less than 2 weeks) and in a low-concentration suspension; however, it can have harmful effects if used in excess or over a long period of time.

Conclusion: Further studies will also be required to study these effects and their mechanism of action in detail.

Keywords: myrrh, chlorhexidine gluconate, tetracycline, mouthwash, wound healing

\section{Introduction}

The use of herbs as medicine is becoming increasingly common, either as home remedies or as complementary and alternative medicines. Myrrh is a well-known herb that is widely used as a home remedy in Saudi Arabia. ${ }^{1,2}$ It is an oleo-gum resin obtained from the tree Commiphora molmol, and the shrub-like tree Balsamodendron myrrh, which grow in the northern and eastern parts of Africa and Arabia. ${ }^{3-7}$ Myrrh consists of $7 \%-17 \%$ volatile oil, $25 \%-40 \%$ resin, $57 \%-61 \%$ gum, and $3 \%-4 \%$ impurities. ${ }^{3-7}$

Several researchers have discussed the use of myrrh in the treatment of ulcers, schistosoma, fasciolopsis, respiratory catarrh, furunculosis, diabetes, and topically for wounds and abrasions. ${ }^{8-13} \mathrm{C}$. molmol executes its antimicrobial action by stimulating the production of white blood cells and by its direct antimicrobial properties. ${ }^{3-5,11,12,14}$ Myrrh acts as an antimicrobial and antifungal healing tonic and stimulant; it also has carminative, anticatarrhal, expectorant, diaphoretic, vulnerary, local antiseptic, immune stimulant, circulatory stimulant, anti-inflammatory, antiseptic, deodorizing, and astringent properties, and is has even been known to exhibit anti-tumor properties. ${ }^{3-5,11,12,14,16}$ In animals, myrrh exhibits antipyretic and hypoglycemic effects as well as protection against the development of gastric ulcers..$^{5,10,15}$ It is known to stimulate uterine tone and promote uterine blood flow. ${ }^{5}$

The use of myrrh is common among Saudis, but few studies have been conducted on its clinical and general use, side effects, and interactions with other drugs. The purpose of this investigation was to evaluate the effect of myrrh on wound
Correspondence: Azizah Al-Mobeeriek Department of Oral Medicine and Diagnostic Sciences, College of Dentistry, King Saud University, Riyadh, Kingdom of Saudi Arabia

Tel +966 | 4784524 ext 307

Fax+966 I 4784524

Email azizafm200।@yahoo.com 
healing and compare this to chlorhexidine gluconate- and tetracycline-containing mouthwashes in an animal model.

\section{Materials and methods}

All procedures and protocols were approved by the research center and ethical committee of King Saud University, Saudi Arabia. The study was conducted on 100 male rats (Sprague Dawley), aged 30 days and weighing between 230 and $370 \mathrm{~g}$ (mean weight, $284.6 \mathrm{~g}$ ), from King Khalid University Hospital Research Center (Riyadh, Saudi Arabia). Animals were divided equally and randomly into four major groups: three experimental and one control, each of which was further subdivided into five groups containing five rats each, according to the time point at which they were examined. Animals were all labeled and kept in their respective cages at room temperature with automatic light control and free access to food (rat chow) and water. Intra-oral clinical examination was performed, and animals exhibiting abnormalities were excluded. Clinical examination was performed before the animals were sacrificed at 1, 2, 7, 15, or 30 days by an overdose of ether.

\section{Surgical method}

The animals were anesthetized using an intramuscular injection of ketamine $(35 \mathrm{mg} / \mathrm{kg}$ ) and xylazine $(5 \mathrm{mg} / \mathrm{kg})$. Under aseptic conditions, the buccal mucosa were disinfected using iodine swabs, and unilateral incisions were made using a scalpel (number 11). For standardization, all the incisions were approximately $5 \mathrm{~mm}$ in length and extended to the connective tissue on the right side of the buccal mucosa. Margins of the wounds were sutured using 4.0 silk sutures.

\section{Experimental animals}

Wounds were irrigated with $1 \mathrm{~mL}$ of $0.2 \%$ myrrh solution (fine powdered myrrh obtained from a traditional market, diluted in $0.9 \%$ sodium chloride). Irrigation was performed on the day of surgery and three times per week thereafter at the site of the closed incision until the day of sacrifice. The second and third experimental groups were similarly irrigated with $0.2 \%$ chlorhexidine gluconate and $0.25 \%$ tetracycline (tetracycline diluted in $0.9 \%$ sodium chloride), respectively. All irrigations were performed at the same time on the same day without anesthesia.

\section{Control animals}

The incision site was rinsed with $1 \mathrm{~mL}$ of $0.9 \%$ sodium chloride irrigation solution on the day of the surgical procedure and three times per week thereafter.
Animals were observed closely during the experimental period for any sign of pain or distress. Animals were examined prior to surgery, during remedy application, and at the time of sacrifice. Clinical examinations focused on changes in the oral mucosa color, infection, and abnormal healing and bleeding.

Animals were sacrificed at 1, 2, 7, 15, 30 days by excess diethyl ether inhalation. The area containing the surgical wound was subsequently excised and stored in neutral $10 \%$ formalin for at least 24 hours. After routine laboratory processing, specimens were embedded in paraffin, and $4 \mu \mathrm{m}$ thick sections were obtained. All sections were examined under a light microscope.

\section{Results}

The groups were compared according to time factors, oral mucosal epithelial lining regeneration, and healing. The results are summarized in Table 1.

\section{Twenty-four hours}

All groups showed discontinuity of the epithelium, severe acute inflammation with polymorphonuclear leukocytes (PMNs), massive infiltrate, engorged blood vessels, and fibrinous exudates. The myrrh group demonstrated purulent exudates and saline-group abscess formation (Figure 1).

\section{Forty-eight hours}

There were mixed (chronic and acute) inflammatory cells, which included: PMNs, mast cells, macrophages and lymphocytes, and vasodilatation. The myrrh group displayed foreign-body reaction. The saline group exhibited more inflammation than others. Both the tetracycline group and the controls showed more acute inflammatory cells compared with others (Figure 2).

\section{One week}

All experimental groups had less inflammation than the control groups. They displayed chronic inflammatory cells with congested blood vessels. There were some scattered PMNs, angiogenesis, and more mast cells in the myrrh group.

\section{Two weeks}

All groups had normal intact mucosa with scant chronic inflammatory mucosa except the myrrh group, which demonstrated massive acute inflammation and necrosis (Figures 3 and 4).

\section{Four weeks}

All groups displayed normal mucosal structure, but the myrrh group displayed more mast cells than others (Figure 5). 
Table I Histological parameter scores for all groups

\begin{tabular}{|c|c|c|c|c|c|}
\hline Group & Histological parameter & Tetracycline & Chlorhexidine gluconate & Myrrh & Control \\
\hline \multirow[t]{9}{*}{24 hours } & Mucosal continuity & 0 & 0 & 0 & 0 \\
\hline & Granulation tissue & 0 & 0 & 0 & 0 \\
\hline & Necrosis & 0 & 0 & + & ++ \\
\hline & Vascularity & + & ++ & + & + \\
\hline & PMNs & +++ & + & ++ & +++ \\
\hline & Macrophages & 0 & 0 & 0 & 0 \\
\hline & Lymphocytes & 0 & 0 & 0 & 0 \\
\hline & Plasma cells & ++ & + & ++ & ++ \\
\hline & Fibroblasts & 0 & 0 & 0 & 0 \\
\hline \multirow[t]{9}{*}{48 hours } & Mucosal continuity & 0 & 0 & 0 & 0 \\
\hline & Granulation tissue & 0 & 0 & 0 & 0 \\
\hline & Necrosis & 0 & + & + & ++ \\
\hline & Vascularity & ++ & ++ & ++ & ++ \\
\hline & PMNs & ++ & + & + & +++ \\
\hline & Macrophages & + & + & + & + \\
\hline & Lymphocytes & + & + & + & + \\
\hline & Plasma cells & ++ & + & + & ++ \\
\hline & Fibroblasts & 0 & 0 & + & 0 \\
\hline \multirow[t]{9}{*}{ I week } & Mucosal continuity & +++ & +++ & +++ & +++ \\
\hline & Granulation tissue & +++ & ++ & ++ & ++ \\
\hline & Necrosis & 0 & 0 & 0 & 0 \\
\hline & Vascularity & ++ & + & +++ & + \\
\hline & PMNs & 0 & 0 & + & 0 \\
\hline & Macrophages & + & + & + & +++ \\
\hline & Lymphocytes & + & + & 0 & + \\
\hline & Plasma cells & ++ & ++ & ++ & ++ \\
\hline & Fibroblasts & ++ & ++ & ++ & ++ \\
\hline \multirow[t]{9}{*}{2 weeks } & Mucosal continuity & +++ & +++ & +++ & +++ \\
\hline & Granulation tissue & ++ & ++ & ++ & ++ \\
\hline & Necrosis & 0 & 0 & +++ & 0 \\
\hline & Vascularity & + & + & + & + \\
\hline & PMNs & 0 & 0 & +++ & 0 \\
\hline & Macrophages & + & + & + & + \\
\hline & Lymphocytes & 0 & 0 & + & 0 \\
\hline & Plasma cells & + & + & ++ & + \\
\hline & Fibroblasts & ++ & ++ & + & ++ \\
\hline \multirow[t]{9}{*}{4 weeks } & Mucosal continuity & +++ & +++ & +++ & +++ \\
\hline & Granulation tissue & + & + & ++ & + \\
\hline & Necrosis & 0 & 0 & 0 & 0 \\
\hline & Vascularity & + & + & + & + \\
\hline & PMNs & 0 & 0 & 0 & 0 \\
\hline & Macrophages & 0 & 0 & + & 0 \\
\hline & Lymphocytes & 0 & 0 & 0 & 0 \\
\hline & Plasma cells & + & + & ++ & + \\
\hline & Fibroblasts & + & + & ++ & + \\
\hline
\end{tabular}

Note: $0=$ none, $+=$ mild, $++=$ moderate, $+++=$ severe $/$ dense.

Abbreviation: PMNs, polymorphonuclear leukocytes.

\section{Discussion}

When compared with natural healing, pharmacotherapeutic agents may be toxic, ineffective, contraindicated, or have serious side effects. Consequently, the use of natural remedies has been on the rise. ${ }^{8,17} \mathrm{~A}$ wide range of traditionally used alternative medicines has been reported in the literature. Many of these medicines are used for chronic diseases, such as chronic renal pathologies, diabetes mellitus, and cancer. ${ }^{17-20}$ Among health care professionals, $51 \%$ of physicians and nurses reported that they had used herbal medication. ${ }^{21}$ Despite the widespread use of herbal remedies, physicians are not always aware of the remedies that their patients use. ${ }^{8,22}$ Additionally, 


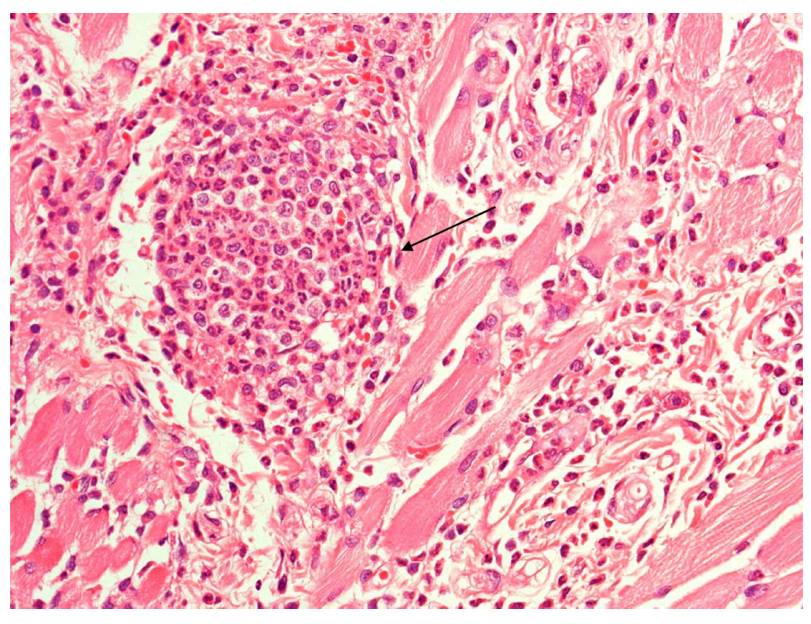

Figure I Severe inflammation and abscess formation in the control group. Notes: Hematoxylin-eosin stain; magnification $\times 40$.

herbs are frequently used concomitantly with conventional medications. ${ }^{22}$

Myrrh is one of the common herbs used in Saudi Arabia. ${ }^{1,2,8}$ Although there is a great deal of published research addressing the potential beneficial effects of myrrh, ${ }^{3-6}$ relatively few studies have addressed its potential adverse effects and toxicity. ${ }^{23-25}$

Wound healing is a complex dynamic process that the body undergoes to eliminate an injury and restore cellular and tissue structures. Wound healing has been divided into three distinct phases: the inflammatory, proliferative, and remodeling phases. ${ }^{26}$

In this study, the experimental groups displayed variable degrees of inflammatory reaction in the first 48 hours. In contrast, the control group displayed a more prolonged and severe inflammatory response, extending up to the first week. Prolonged inflammatory reaction could be attributed to bacterial colonization, lack of immunomodulation, and antibacterial activity.

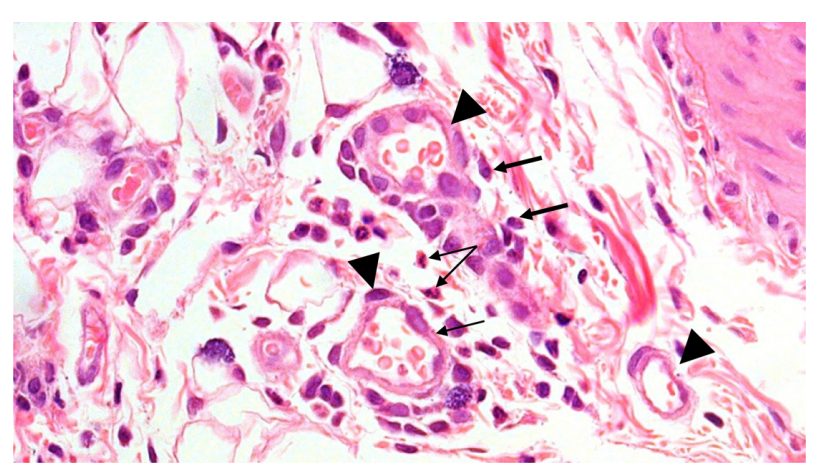

Figure 2 Multiple dilated engorged blood vessels (triangle), polymorphonuclear leukocytes (small arrow), and plasma cells (thick arrow) in the 48-hour group. Notes: Hematoxylin-eosin stain; magnification $\times 40$.

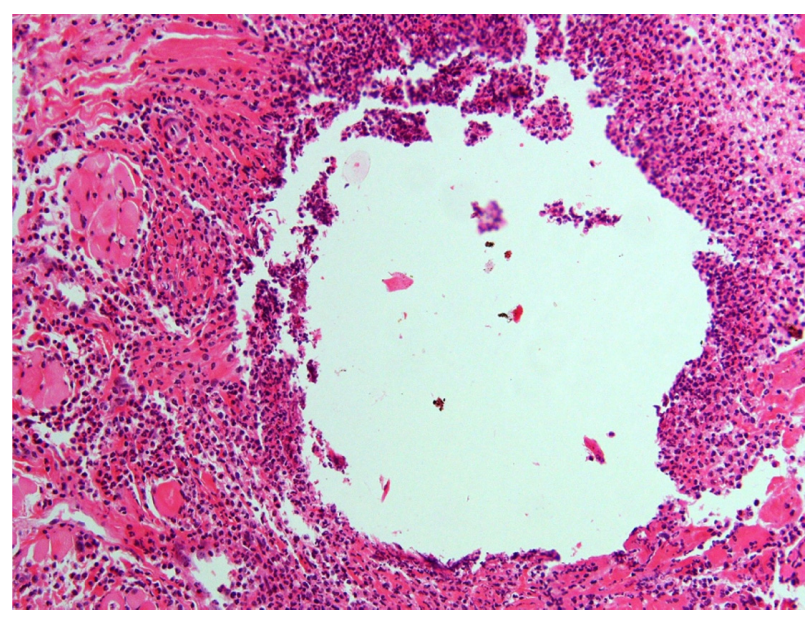

Figure 3 Acute inflammation and necrosis in the 2-week myrrh group. Notes: Hematoxylin-eosin stain; magnification $\times 20$.

The remodeling stage started earlier in the myrrh group than in the other groups. The myrrh group also displayed good immunomodulation and antibacterial/fungal responses. Similarly, Kimura et al reported that myrrh has a more marked effect on adjuvant-induced granuloma than other anti-inflammatory preparations such as hydrocortisone. ${ }^{10}$

Previous studies have indicated that myrrh acts as an antiseptic, anti-inflammatory, and a circulatory and immune system stimulant. ${ }^{3-5,11,12}$ It has also been shown to stimulate plasma cell production and induce angiogenesis and, therefore, remodeling within 7 days of an injury occurring. ${ }^{27,28}$ Accordingly, myrrh may be potentially useful in the induction of wound healing and repair.

However, in this study, the prolonged use of myrrh induced severe combined acute and chronic inflammation and necrosis. This is most likely the result of an overdose and

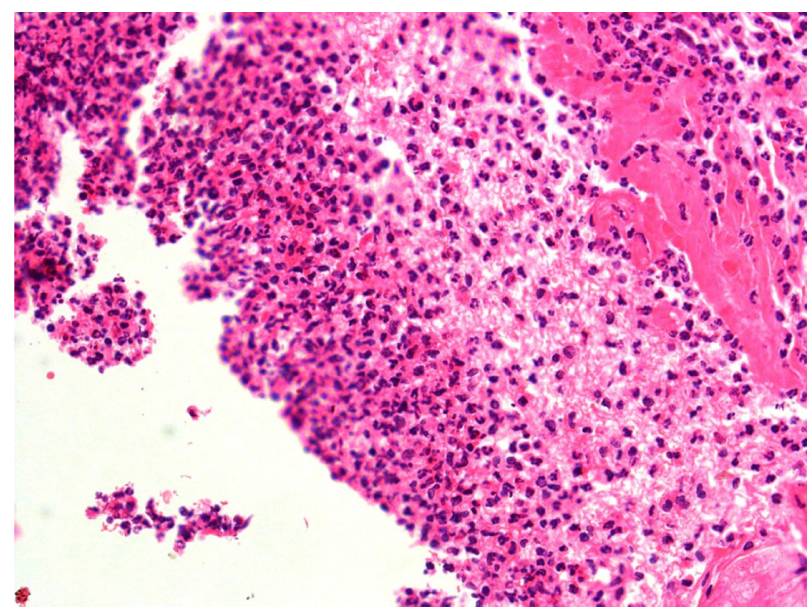

Figure 4 Closer view showing acute inflammation and necrosis in the 2-week myrrh group.

Notes: Hematoxylin-eosin stain; magnification $\times 40$. 


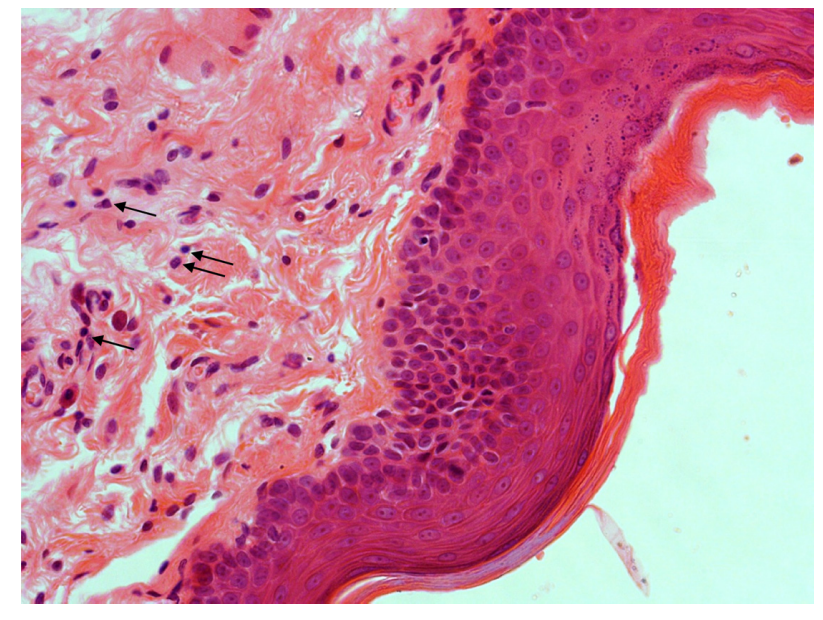

Figure 5 Complete healing in the myrrh group at 4 weeks, as indicated by the plasma cells (arrows).

Notes: Hematoxylin-eosin stain; magnification $\times 40$.

toxicity or the initiation of an overwhelming body response to the myrrh. It could thus be assumed that the healing and repair of damaged tissue through the use of myrrh is limited to its use over a short period of time and in low concentration.

An additional benefit of myrrh is its antibacterial properties, since only the control animals showed bacterial colonization. A decrease in the incidence of wound sepsis with myrrh treatment may therefore be anticipated. This is of particular interest with the emergence of resistant bacterial strains. The use of myrrh may decrease wound morbidity, treatment costs, and health care requirements, and have a positive effect on healing. ${ }^{29}$ Wound infection, however, may delay host defense and healing. ${ }^{30}$ The use of topical antimicrobial agents, such as honey and essential oils, has been suggested for preventing wound infections as an alternative to antibiotics. ${ }^{30}$ Myrrh could therefore be used as an adjunct to or a substitute for the currently used therapies.

The research additionally indicated that the use of myrrh for a short period of time (less than 2 weeks) aids in the process of healing. The investigation demonstrated that myrrh is biocompatible with soft and even hard tissues to some extent, since it induced a severe inflammatory reaction in the rats (rather than an autoimmune reaction). In addition, the oleo-resin present in myrrh has been shown to be more toxic than its oil. ${ }^{31}$ It can therefore be assumed that its toxicity is dose dependent.

\section{Conclusion}

Even though myrrh is popularly used in Saudi Arabia as a topical remedy (mouthwash) for healing and treatment of infection, it should be used with caution. Prolonged use of myrrh in high concentrations on open wounds, which is how it is commonly used by Saudis, should be avoided because of its toxicity and inflammation-inducing properties. The overuse of myrrh may also trigger unregulated inflammation, which could result in poor healing of wounds. Myrrh use should thus be regulated. In general, all herbs and/or drugs should be sold with information about the risk of drug interactions, side effects, and toxicity.

The utilization of herbs for medicinal purposes has dramatically increased worldwide. Further research is required to clearly determine the various properties of these herbs, their optimal doses, forms, and their adverse effects and toxicity. Other factors should be also considered, such as the type, size, and location of the wound, as well as vascular supply, infection, and other conditions that might complicate the healing process.

This study indicated that the response to a concentrated dose of myrrh can be very toxic locally, causing pronounced inflammation (especially if the wound is open). The toxicity of myrrh may therefore preclude its use in the raw form, but it could be used in solution. A controlled and low concentration of myrrh solution could aid in faster healing as an adjunct or as a replacement for the current therapies available.

\section{Disclosure}

The author reports no conflicts of interest in this work.

\section{References}

1. Bakhotmah and Alzahrani. Self-reported use of complementary and alternative medicine (CAM) products in topical treatment of diabetic foot disorders by diabetic patients in Jeddah, Western Saudi Arabia. BMC Res Notes. 2010;(3):254.

2. Al-Faris E, Al-Rowais N, Mohamed AG, et al. Prevalence and pattern of alternative medicine use: The results of a household survey. Ann Saudi Med. 2008;28(1):4-10.

3. Massoud A, El Sisi S, Salama O, Massoud A. Preliminary study of therapeutic efficacy of a new fasciolicidal drug from Commiphora molmol (myrrh). Am J Trop Med Hyg. 2001;65(2):96-99.

4. Sheir Z, Nasr AA, Massoud A, et al. A safe, effective herbal antischistosomal therapy derived from myrrh. Am J Trop Med Hyg. 2001;65(6):700-704.

5. Michie CA, Cooper E. Frankincense and myrrh as remedies in children. J R Soc Med. 1991;84(10):602-605.

6. Hillson RM. Gold, frankincense and myrrh. J R Soc Med. 1988;81(9) 542-543.

7. Hanus LO, Rezanka T, Dembitsky VM, Moussaieff A. MyrrhCommiphora chemistry. Biomed Pap Med Fac Univ Palacky Olomouc Czech Repub. 2005;149(1):3-27.

8. Al-Rowais NA. Herbal medicine in the treatment of diabetes mellitus. Saudi Med J. 2002;23(11):1327-1331.

9. Borrelli F, Izzo AA. The plant kingdom as a source of anti-ulcer remedies. Phytother Res. 2000;14(8):581-591.

10. Kimura I, Yoshikawa M, Kobayashi S, et al. New triterpenes, myrrhanol $\mathrm{A}$ and myrrhanone $\mathrm{A}$, from guggul-gum resins, and their potent antiinflammatory effect on adjuvant-induced air-pouch granuloma of mice. Bioorg Med Chem Lett. 2001;11(8):985-989. 
11. Shonouda ML, Farrag RM, Salama OM. Efficacy of the botanical extract (myrrh), chemical insecticides and their combinations on the cotton leaf worm, Spodoptera littoralis boisd (Lepidoptera: Noctuidae). J Environ Sci Health B. 2000;35(3):347-356.

12. Buckley SA, Evershed RP. Organic chemistry of embalming agents in Pharaonic and Graeco-Roman mummies. Nature. 2001;25; 413(6858):837-841.

13. Tonkal AM, Morsy TA. An update review on Commiphora molmol and related species. J Egypt Soc Parasitol. 2008;38(3):763-796.

14. Yakoot M. A short review of the anthelmintic role of Mirazid. Arq Gastroenterol. 2010;47(4):393-394.

15. Al-Harbi MM, Qureshi S, Raza M, Ahmed MM, Afzal M, Shah AH. Gastric antiulcer and cytoprotective effect of Commiphora molmol in rats. J Ethnopharmacol. 1997;55(2):141-150.

16. Mazzio EA, Soliman KFA. In vitro screening for the tumoricidal properties of international medicinal herbs. Phytother Res. 2009; 23(3):385-398.

17. Otoom SA, Al-Safi SA, Kerem ZK, Alkofahi A. The use of medicinal herbs by diabetic Jordanian patients. J Herb Pharmacother. 2006; 6(2):31-41.

18. Wojcikowski K, Stevenson L, Leach D, Wohlmuth H, Gobe G. Antioxidant capacity of 55 medicinal herbs traditionally used to treat the urinary system: a comparison using a sequential three-solvent extraction process. J Altern Complement Med. 2007;13(1):103-110.

19. Garrow D, Egede LE. National patterns and correlates of complementary and alternative medicine use in adults with diabetes. J Altern Complement Med. 2006;12(9):895-902.

20. Mao JJ, Farrar JT, Xie SX, Bowman MA, Armstrong K. Use of complementary and alternative medicine and prayer among a national sample of cancer survivors compared to other populations without cancer. Complement Ther Med. 2007;15(1):21-29. Epub 2006 Sep 28.
21. Gardiner P, Legedza A, Woods C, Phillips RS, Kemper KJ. Herb use among health care professionals enrolled in an online curriculum on herbs and dietary supplements. J Herb Pharmacother. 2006;6(2):51-64.

22. Saw JT, Bahari MB, Ang HH, Lim YH. Herbal use amongst multiethnic medical patients in Penang Hospital: Pattern and perceptions. Med J Malaysia. 2006;61(4):422-432.

23. Rao RM, Khan ZA, Shah AH. Toxicity studies in mice of Commiphora molmol oleo-gum-resin. J Ethnopharmacol. 2001;76(2):151-154.

24. Omer SA, Adam SE. Toxicity of Commiphora myrrha to goats. Vet Hum Toxicol. 1999;41(5):299-301.

25. Omer SA, Adam SE, Khalid HE. Effects on rats of Commiphora myrrha extract given by different routes of administration. Vet Hum Toxicol. 1999;41(4):193-196.

26. Kumar V, Cotran RS, Robbins SL. Basic pathology. Ch3: Tissue repair: cellular growth, fibrosis and wound healing. 7th ed. Philadelphia: Saunders; 2004.

27. Russo A, Russo G, Peticca M, Pietropaolo C, Di Rosa M, Iuvone T. Inhibition of granuloma-associated angiogenesis by controlling mast cell mediator release: Role of mast cell protease-5. Br J Pharmacol. 2005;145(1):24-33.

28. Young J, Liu C, Butler G, Cohn Z, Gallitt S. Identification, purification, and characterization of a mast cell-associated cytolytic factor related to tumor necrosis factor. Immunology. 1987;84(24):9175-9179.

29. Ashcroft GS, Mills SJ, Ashworth JJ. Ageing and wound healing. Biogerontology. 2002;3(6):337-345.

30. Bowler PG. Wound pathophysiology, infection and therapeutic options. Ann Med. 2002;34(6):419-427.

31. Massoud AM, Labib IM, Rady M. Biochemical changes of Culex pipiens larvae treated with oil and oleo-resin extracts of Myrrh Commiphora molmol. J Egypt Soc Parasitol. 2001;31(2):517-529.
Clinical, Cosmetic and Investigational Dentistry

\section{Publish your work in this journal}

Clinical, Cosmetic and Investigational Dentistry is an international, peer-reviewed, open access, online journal focusing on the latest clinical and experimental research in dentistry with specific emphasis on cosmetic interventions. Innovative developments in dental materials, techniques and devices that improve outcomes and patient satisfac-

\section{Dovepress}

tion and preference will be highlighted. The manuscript management system is completely online and includes a very quick and fair peerreview system, which is all easy to use. Visit http://www.dovepress. com/testimonials.php to read real quotes from published authors. 